théorie de l'objectivité en histoire et dans les sciences socialess, en $\mathrm{G}$. Simmel: Les problemes de la philosophie de thistoire, edicion al cuidado de $\mathbf{R}$. Boudon, Paris, P.U.F, 1984.

26. Ver nota 16.

27. Intervención de Popper en debate del Simposio de Burgos (1968), en Ensayos de Filosolfo de la Ciencia, Madrid, Tecnos, 1970.

28. En lo que sigue nos fijannos en los trabajos de Elster, «La posibilidad de una política racionals, recogido en L. Olive (comp.) (op. cit.), pp. 132-176, traduccion de Adriana Sandoval, y su comentario a las propuestas de van Parijs y van der Veen de transición capitalista al comunismo mediante el salario universal garantizado («universil grant ) recogido en Theory and Soctety, 15 (1986). Algunos de estos últimos materiales los conocl gracias a Fdo. Aguiar quien realiza en la UNED un trabajo de doctorado sobre elección social.

29. Que para todos sea posible ser atendido en la sanidad pública no significa que sea posible atender a todos en esa red sanitaria. Para detalles sobre esta noción, véase Elster: Logic and Society. 1978, y Making sense of Marx, p. 44, donde se relaciona este tema con la noción de contradicción social y algunos aspectos que considera recuperables del razonar dialéctico.

30. Término que hablando de maxismo nos hace recordar, aunque no se refiera al tema aquí estudiado. el muy recomendable libro de Fco. Fdez Buey: Contribucion a la critica del marxismo cientificista, Barcelona, Edicions Universitat de Barcelona, 1984.

\title{
Del análisis a la pragmática. Las nuevas ínfulas de un viejo estilo
}

\section{JULIO SEOANE}

El primer objetivo de Rorty es la filosolía analítica. No creo que haga falta decir que esta filosofía ha conformado el pensamiento americano desde los años treinta, de tal forma que todo filósofo podría hacer suyo el canto que se deja leer en la introducción a Consequences of Pragmatism uen un principio todos fuimos positivistas». Con todo, sería absurdo suponer que este modo de enfrentarse a la filosofía fue uniforme y poco ajeno a disidencias; en verdad, la historia del positivismo es la historia de una forma de pensar que cuanto más profundizaba en sus propuestas y problemas, más tendía a formar nuevas propuestas y problemas que llevaban a elaboraciones cada vez más alejadas del ideal del «análisis del lenguaje». No ha sido un movimiento estático, sino, muy al contrario, un pensamiento tan dinámico que ha llegado a socavar sus cimientos.
Rorty mismo ha señalado que con la aparición en el panorama filosófico de pensadores como Rawls, Khun o Sellars el positivismo ha culminado y se ha evaporado (la situación de Rawls es reveladora para Rorty, porque es la admisión de un interés por problemas que no se plantean desde la óptica de la filosofía analítica y ni siquiera son propios de la filosofía puesto que Rawls ha interesado a sociólogos, juristas, etc.): «[...] la filosofia analítica culmina en Quine, el último Wittgenstein, Sellars y Davidson, lo cual es decir que se trasciende y cancela a sí mismaw; y esto no es casual puesto que el prejuicio rigorista de este tipo de reflexión filosófica imponía unos márgenes tan estrechos al concepto de racionalidad que, como dice Putnam, no daban cabida ni a la posibilidad de crear una filosofía analítica.

La filosofia y el espejo de la naturaleza 
es, en buena parte, la recusación de la filosofía analítica principalmente por ser realista, esto es, por creer que existen entidades en la realidad que se corresponden con las que su quehacer halla; de este modo considera que existen verdades exteriores a nuestras propias construcciones intelectuales y que un buen análisis y depuración del lenguaje posibilita que éste se refiera directamente a esas verdades. ${ }^{2}$ Éste es el mito del conocimiento como espejo de la naturaleza que viene generado por una veta "positivistan que Rorty sitúa en su comienzo en Descartes. Aquí empieza la gran crítica del pragmatismo rortyano al positivismo; para ello se ayuda de lo que llama la otra gran corriente de la filosofía contemporánea, esto es, la hermenéutica. La hermenéutica (hay que decir que su comprensión por parte de Rorty es muy particular) es, frente al realismo positivista, negativa en tanto considera que la ocupación cientificista es unidireccional y equivocada: el lenguaje crea metáforas y con ellas realidades que pueden multiplicarse, pero, sobre todo, que se hacen dependientes de nuestra actividad dentro del lenguaje. ${ }^{3}$ En algún momento, Rorty se pregunta por el vinculo que pueda unir a Heidegger y Derrida, y contesta que éste no sería otro sino el deseo de poetizar la filosofía; de ellos toma Rorty su crítica al positivismo $y$ al realismo que comporta, pero él no desea poetizar la filosofía, sino, al menos en un principio, politizarla, darle una función social dentro del deseo de los fundadores del pragmatismo americano.

Con Quine y Sellars entra en crisis el concepto de verdad que el análisis sostenía, con Davidson lo debemos abandonar. Este último es el gran héroe de Rorty, que considera su obra como la liquidación definitiva del paradigma heredado (del cual el mismo Rorty fue uno de los últimos y no menos importantes mentores) ${ }^{4}$ y la puesta en claro de lo que debemos tener en cuenta a la hora de pensar "de nuevo". Es el gran almacén donde Rorty recupera fuerzas y argumentos cuando la crítica le agobia. Quine y Sellars demucstran ya que explicamos un lenguaje en referencia a nuestras creencias: es imposible especificar un punto arquimédico no intencional y alejado dcl lugar donde nuestro particular lenguaje se desarrolla, si queremos que éste se refiera al mundo; pero Rorty siempre les termina echando en cara su excesiva vinculación con preocupaciones tradicionales: buscan no sólo una manera de contrastar la teoría con el mundo, sino una razón para creer que perseverar en ella da el mejor conocimiento de la realidad. ${ }^{5}$ Para Rorty, Davidson no tiene esas pegas cuando muestra que explicamos un lenguaje on referencia a lo que hacemos, es decir, que el concepto de verdad es parcialmente autorreferencial: se trata de "explicar la verdad en términos del lenguaje que se conoce ${ }^{6}$

Aquí se encuentran ya las dos grandes críticas que, haciendose a la filosofía analítica, se hacen, o se intentan hacer, a toda la filosofia occidental, y vertebran el origen del pensamiento de Rorty. Se trata de la crítica al conocimiento y la crítica a la verdad.

\section{Acerca del conocimiento}

En La filosoffa y el espejo de la naturaleza $a^{7}$ elabora Rorty todo un programa de crítica a la epistemología modema que sitúa como iniciada por Descartes. El libro resulta una destructora crítica de la teoría del conocimiento y no tanto del conocimiento mismo, en la medida que parece desprenderse de sus premisas que no existe algo así como conocimiento a secas o, cuando menos, no existe en la modernidad. Desde Des- 
cartes asistimos a la unión del conocer y del discurso que habla sobre el conocer, de forma tal que resulta imposible hablar de conocimiento sin hacer, al mismo tiempo, una epistemología. Es evidente que esto pudiera resultar así también en otras épocas de la historia de la humanidad $(o$, incluso, que sea connatural al modo de pensar humano), pero lo característico de la era moderna es el modo en que el conocimiento -o su teoría- es concebido, es decir, el considerar que el conocimiento es un "espejo de la naturaleza", y que la tarea encomendada a todo discurso que hable sobre el espontáneo reflejo que la mente humana concede al mundo es la de pulir de forma tal el espejo, que sus imágenes sean idénticas al original. El modelo cartesiano que se toma como el condicionante de toda epistemología moderna, lleva a pensar que el conocimiento sensitivo es la base del verdadero saber racional, que no sería sino la sensación recubierta de un revestimiento lingüístico que la introduce en el juego de las intcligencias humanas. De esta forma, el interés supremo que se concibe desde la Ilustración hasta nuestros días es cómo poder especular sin alcjarnos del fundamento -sensible- de nuestra especulación. Las estructuras que nuestro conocimiento crea para dar cuenta del mundo son análisis que forman entes inexistentes que se supone subyacen a la realidad. Pero tal suposición no deja de ser una hipótesis indemostrada e indemostrable; "la reclamación de conocer nuestras facultades cognitivas o la naturaleza del lenguaje es no menos "metafísicamente dogmática" que la de reconocer que el intelecto activo se parece al divino en ser actus purus s. ${ }^{8}$ La explicación da una comprensión de los hechos (nos hace entender una sinfonía o un libro o un hecho determinado), pero la conexión que tal comprensión establece es interna y no causal, se establece entre lo explicado y la explicación sin tener por qué suponer que una causa a la otra. Es así que la búsqueda de entidades ocultas que actúen de cau* sa de la realidad no es otra cosa que un fdolo filosofico. No existe una teoría propiamente descriptiva que pueda ser objeto de la calificación de verdadero o falso neutralmente; en verdad, la descripción se une a la reflexión moral (a las exigencias del mantenimiento de la vida práctica, al lenguaje «que se conocen) y no nos permite pensar que las verdades son clasificables según su mayor o menor proximidad a la realidad: tienen valor en tanto son efectivas. ${ }^{9}$

"La palabra conocimiento no parecería digna de que se luchara por ella si no fuera por la tradición kantiana de que ser filósofo es tener una "teoría del conocimiento" y la tradición platónica de que la acción que no está basada en el conocimiento de la verdad de las proposiciones es irracional ${ }_{*}{ }_{10}^{10}$ sin tales tradiciones deberiamos considerar el conocimiento mejor según la sugerencia rortyana: una forma de arreglárnoslas en el mundo, donde la objetividad no es el encuentro con la verdad, sino más bien conformidad con normas de justificación. Conformidad que no es base de las prácticas de justificación aun cuando sí las configure (al cabo, es una de las justificaciones posibles); pero en la medida en que no existe un vocabulario de vinculación privilegiada con la realidad (ya hemos visto que es ficticia la imagen de que la realidad "choca" con nuestro cuerpo e imprime una imagen que se expresa en el lenguaje y se corresponde de forma fiel con ella), no podemos considerar que la objetividad pueda existir, ni siquiera que la verdad pueda ser considerada. ${ }^{11} \mathrm{Ni}$ existen mecanismos neutrales para conocer, ni tampoco nada ajeno a las imágenes y metáforas que nuestro mismo lenguaje crea. 


\section{Acerca de la verdad}

La diferencia entre el último filósofo analítico, el que aguanta tras varios años de criticas internas, y Rorty es la que hay entre alguien que toma en serio la pregunta « $\dot{i}$ existe realmente aquello de lo que hablamos? que no. ${ }^{12}$ Si hemos visto que el problema de la verdad es un absurdo típico de una época determinada y que no existe una verdad extraña a la propia elaboración que el conocimiento del hombre realiza, debemos concluir con una de las más típicas ideas de Rorty: la verdad se realiza desde el mismo lenguaje. ${ }^{13}$ No hay una verdad ajena al hombre porque no existe una representación del mundo que no la contenga en sus intereses; frente a la verdad como correspondencia entre la proferencia emitida y la cosa, Rorty opone una correspondencia en un sentido trivial: es verdad si funciona. ${ }^{14}$ Desde este punto de vista, ni el mundo, ni nuestro conocimiento de él son independientes de nuestros intereses y asunciones; «la cuestión sobre si considerar la verdad como "correspondencia con la realidad" o como "garantía de asertabilidad" es la cuestión sobre si tratar el lenguaje como una representación o como un juegon. ${ }^{15}$ No es necesario advertir que Rorty se inclina por la segunda opción que trata a la verdad como propiedad de las afirmaciones y no de lo afirmado. ${ }^{16}$ La cuestión sobre la verdad es una cuestión sobre el modo de uso del lenguaje dentro de la especie humana, y si aceptamos la posición rortyana, deberemos de acceder a considerar al lenguaje como el instrumento por el que los intereses y objetivos de los hombres se especifican y planean caminos y justificaciones que los hagan efectivos y con cierta pregnancia. $Y$ no significa que la verdad se encuentre en el lenguaje, simplemente que es la crea- ción de metáforas determinadas y de imágenes linguíisticas específicas la que determina las herramientas con las que hemos de acometer el mundo: "Decir que deberíamos abandonar la idea de la verdad "ahí fuera" esperando ser descubierta no es decir que hemos descubierto que la verdad no está "ahí fuera". Es decir, que nuestros propósitos serian mejor servidos si cesáramos de ver la verdad como una materia profunda, como un asunto de interés filosófico».17 La historia de la verdad se presta mejor a ser una historia de las metáforas que una historia del descubrimiento.

El lenguaje ha de tomarse como un conjunto de herramientas alternativas y no como piezas que se juntan y dan la correcta y exacta réplica del mundo. Estas herramientas son metáforas que crean imágenes y modos de aproximación a la realidad diferente: no es que varíe el mundo y con él la verdad, sino que nuestro acercamiento a él puede girar en una dirección totalmente nueva. $^{18}$ Lo verdaderamente importante es mantener los niveles conversacionales, puesto que es por ellos que se derivan formas óptimas de manejo de la realidad; la función del lenguaje es posibilitar que los individuos puedan habérselas con un mundo social y natural con ciertas garantias de éxito: "emitir sentencias es una de las cosas que la gente hace para dar cuenta de su entornom. ${ }^{19}$ Por esto, los lenguajes son «hechos antes que fundados y la verdad es una propiedad de entidades lingüísticas,${ }^{20} \mathrm{y}$ no por ello tiene menos pregnancia ya que, aunque «formada», está haciendo posible la vida de los hombres; el lenguaje no representa el mundo, sino que hace verdad una determinada creencia, y en este hacer verdad se inscriben todas las relaciones humanas que, por mor de la estabilidad de estas verdades contingentes, tienden a perpetuarse. 
Como se puede apreciar, bien por el análisis de la teoría del conocimiento, bien por la exposición de la verdad, Rorty confluye cabezonamente a idénticas conclusiones: no es preciso pulir el lenguaje como antes se creía necesario pulir la mente. Rorty en este punto tiene muy en cuenta que de los pasados intentos que ponían la teoría del conocimiento en el nivel de la búsqueda del modo fiable de reflejar el mundo, se ha pasado con la filosofía analítica a un intento de hacer que el lenguaje sea lo más isomorfo posible con el mundo exterior, con lo que si bien ya no existe un reflejo mental que corresponde a la realidad, es cierto que se impone una suerte de isomorfía más fuerte aun que la del espejo en la que ni siquiera cabe el cambio de perspectivas. ${ }^{21}$

Mas no podemos decir qué es la realidad independientemente de nuestros intereses de manejarnos con ella. Por aquí se afirma que no existe una verdad «ahí fuera». Y no podemos explicar el cómo el lenguaje relata el mundo, dando con el modo en que ciertas sentencias pueden ser verdaderas, sino mostrando cómo, con nuestro comportamiento, nos ayuda a arreglárnoslas con el mundo. Aquí se afirma la contingencia. Entre ambas afirmaciones se sitúa el "giro lingúístico» que Rorty está presto a abrazar.

\section{La conversación social}

Es este decidido enfrentamiento con las tesis realistas to que permite a Rorty soslayar las morales de corte analítico y enfrentarse a las continentales. A las primeras les acusa de hacerse intuicionistas o emotivistas ante la imposibilidad de encontrar una verdad externa que se corresponda con las reflexiones morales; cuando no existe ya interés en encontrar esa "visión divina" del mundo, entonces no tenemos moti- vos para caer en la "desesperación» y hacemos intuicionistas o emotivistas. Contra las segundas argumenta Rorty que pecan de "positivistas", esto es, que intentan buscar una verdad que legitime nuestras morales y políticas sin caer en la cuenta de que la autoreferencialidad del lenguaje, entre otras cosas, crea metáforas adecuadas a un momento y lugar.

Es peculiar que ante esto, Rorty, como dice Bernstein. ${ }^{22}$ no deba ser acusado ni de historicista (porque no cree en una teoría de la historia), ni de nihilista (puesto que a lo largo de toda su obra da valores fácilmente perceptibles - los de las sociedades liberalesy nos insta a defenderlos), ni de relativista (en tanto que cree en la verdad aunque sin títulos honoríficos de objetividad y eternidad --la verdad en sentido pragmático es tan vinculante "como cualquier otra"-), ni de escéptico (ya que no cree que exista una verdad incognoscible). ${ }^{23}$ «El pragmatista desea definir tanto el ideal epistemológico como el ético - la verdad tanto como el Bien- en términos de continuar en la presente línea tanto como podamos antes que en términos de correspondencia con algo externow; ${ }^{24}$ podemos creer en algo y justificarlo, pero ya no con razones, sino con redescripciones nuevas de la realidad que se muestran más adecuadas. Con una nueva apologética.

De este modo, la justificación no puede ser ya una especial relación entre ideas o palabras y objetos, sino una consecuencia de práctica social. Es un mito el derivar comportamientos desde principios universales, ni éstos son posibles, ni el individuo puede proceder de tal modo en tanto no existen valores tales como la racionalidad o el desinterés al margen de los patrones educativos y, en definitiva, "la aplicación de títulos honoríficos como "objetivo" y 
"cognitivo" no es nunca más que la expresión de un acuerdo". 25 Y no un acuerdo consensuado bajo un lenguaje con reclamaciones universales o merced a la racionalidad del ciudadano, sino entre individuos que han de habérselas con la realidad y optan por una determinada manera y no por otra, que les condicionará sin hacerles creer que es la única alternativa posible. La apuesta se media con la historia que acaece en un momento dado. Es contingente.

Es evidente que tal contingencia solamente es posible dentro de las democracias occidentales, por lo que se nos está exigiendo la opción por un «nosotros» muy determinado, ${ }^{26}$ que si evita la acusación de decisionismo, es porque desde el principio se nos ha dicho que somos hijos de una determinada visión del mundo que es la única que nos dice que no hay tradiciones y que lo mejor que podemos hacer es dejar proliferar las redescripciones del mundo. Bien es cierto que mitigar el decisionismo con algodones historicistas, aunque perfumados, no es solventarlo, pero, al cabo, creo que ésta no es peor solución que pretender optar por un consenso racional o por una supuesta naturaleza común (a esto, Rorty agrega que es, como se verá, la única forma de defender hoy el liberalismo con garantías). La posición rortyana se ve clara en lo que él llama el ejemplo clave de las modernas teorias sociales: ante Auswitch no se puede demostrar la bajeza moral y lo poco acorde de tales acciones con la humanidad, es preferible intentar convencer - aun con trampasde que es una posición menos ventajosa que su opuesta. En último término, la objetividad se ha de reemplazar por la solidaridad en una comunidad: éste es el único origen de nuestras verdades sociales. ${ }^{27}$ Las sociedades no son cuasi personas, son «compromisos entre per-
Sonas ${ }^{28}$ y estos compromisos no son con mayúsculas; pero, porque Sócrates no pueda responder a Trasímaco no se sigue que éste esté dejado de los compromisos sociales. Comunidad es compromiso contingente, pero no por ello falto de fuerza.

Frente a la justificación por el conocimiento se impone la justificación conversacional que haría justicia al establecimiento de las metáforas en el mundo. En el lado opuesto está la confrontación que haría neutral cualquier evaluación (tanto científica como moral o penal). La confrontación es la hipostatización de una teoría del conocimiento por la cual se ha optado, es el tradicional deseo de sustituir la inseguridad de la conversación por la estable confrontación con los hechos. Pero tal sustitución no deja de ser arbitraria. ${ }^{29}$

Una vez que hemos rechazado la noción de validez absoluta no me parece muy descabellado que, como Rorty hace, se deba admitir que los cambios no se dan por convicción racional, sino por valores externos. Una convicción (como es la de la confrontación) que puede ser justificada por cualquiera, que incluso personas malvadas se puede argüir que entran en su aceptación, no es capaz de dividir y señalar la sociedad que nos interesa y por ello tiene poco interés. ${ }^{30} \mathrm{Y}$ lo que es peor, se puede argüir que no tiene excesivo valor para defender el liberalismo que es el verdadero propósito del programa rortyano. Al no existir una verdad externa que guíe nuestras creencias y discusiones, se ha de admitir que el convencimiento racional se sustituye por la persuasión apologética; si «son imágenes más que proposiciones, y metáforas más que afirmaciones, lo que determina la mayor parte de nuestras convicciones filosóficass ${ }^{31}$ y sociales, entonces uno hay una manera clara de dibujar la línea entre persuasión y fuerza, y 
de este modo tampoco una manera clara de dibujar una línea entre una causa del cambio de una creencia que sea también una razón y una que sea una "mera" causan. 32

\section{La nueva sociedad liberal}

La libertad, que es el valor consustancial a las sociedades modernas -que, repito, en el decir de Rorty debemos imperiosamente defender-, es el reconocimiento de la contingencia, es decir, el integrarse dentro de la historia que hace invalida una fundamentación con valor eterno. La defensa de las democracias occidentales (al modo de un "burgués postmoderno*) necesita de la invención de nuevas metáforas más que de una fundamentación. "El pragmatismo es antitético con el racionalismo ilustrado, pero el mismo ha sido hecho posible solamente por el racionalismo ilustrado y ahora sirve como vocabulario de un maduro liberalismo ilustrado, $x^{33}$ Nada más lejos de la idea que conformó la modernidad, pero también, en origen, nada más acertado porque, en mi opinión, debemos admitir que el liberal que la modemidad trajo había de integrarse en la historia y formar sociedades donde su libertad fuera defendida a ultranza: era un liberal que formaba sociedades contingentes.

Incluso Rorty llega a decir que lo que caracteriza precisamente a las democracias modernas es su matiz experimental; las sociedades, los modos de organización colectiva han de tomarse como experimentos que pueden o no ser exitosos, pero que, al igual que sucede en la ciencia, no tienen consigo ninguna certeza y sí ganas de conseguir su objetivo; valga aquí una extensa cita: "Jefferson y Dewey describieron América como un "experimento". Si el experimento fracasa, nuestros descendientes podrán aprender algo importante. Pero no aprenderán una verdad filosófica, ni tampoco una verdad religiosa. Simplemente obtendrán algunas indicaciones de lo que deberían tener en cuenta al preparar su próximo experimento. Aunque nada más que eso sobreviva a la èra de las revoluciones democráticas, es posible que nuestros descendientes recuerden que las instituciones sociales pieden ser vistas como experimentos en esfuerzos cooperativos y no como intentos de encarnar un orden universal ahistórico». ${ }^{34} \mathrm{Y}$ es esto lo que hace superflua cualquier ciencia que intente establecer un orden inmutable -0 " "seguros-.

El objetivo a conseguir es la anulación de estas matrices disciplinares que aseguran el acuerdo. Aqui ha de entrar la idea rortyana de que es el poeta mejor que el filósofo el que con su creación de imágenes y metáforas nuevas -su actuación como germen de proliferación de discursos- ha de ocuparse de dar «alternativas sociales». La idea que Rorty tiene del poeta como creador de nuevas metáforas ha pasado por distintas etapas; ${ }^{35}$ desde el creador que coincidía de forma maravillosa con un arreglo pragmático de la sociedad desde la nada, hasta el demiurgo desarraigado de lo social que utiliza su carisma para dar un giro a las metáloras morales y políticas. El final de la aventura ha sido el internar al poeta en la privacidad individual a través de la figura del uironistas y dejar el comportamiento social en una posición poco dada al cuestionamiento y revolución de los conceptos y metáforas establecidas. ${ }^{36}$ De cualquier forma es constante en Rorty la idea de que existe un creador o una función creadora de los hombres que actúa al modo de una hermenéutica pragmática que considera los discursos y su institucionalización en sociedades como societas, es decir, como un 
grupo de personas unidas cada una con sus individuales intereses que intentarán conseguir, y cuyo cemento o aglutinante es más bien la urbanidad (las reglas pragmáticas y convenciones que permiten la convivencia) y no la ley universal y segura. Ni que decir tiene que las teorizaciones políticas se han dixigido siempre hacia lograr una universitas (que observara a las sociedades como grupos unidos por mutuos intereses y en vistas a un fin común) y que la teoría del conocimiento aportaba importantes materiales en tanto era en relación con ella que podía imaginarse algo así como un fin común y un interés compartido por todos los individuos. Aquí la práctica se legitima por su reconstrucción racional, mientras que en la interpretación hermenéutica la práctica se determina por la elección de los elementos, con lo que son siempre la segura fundamentación y el filosofar socrático los que enfrentan la batalla. $^{37}$

Es por esto que la apología es preferible antes que la imposible racionalidad social, que no son necesarias nociones filosóficas para criticar el mundo $y_{s}$ por último, $y$ paradójicamente, que el filósofo se puedc olvidar de la realidad puesto que, al cabo, cualquier ciudadano a buen seguro que lo puede hacer tan bien como él. Esto último es la posición que Rorty señala en su última obra como «ironista». El «ironista», el filósofo rortyano, puede poner en duda la naturaleza del hombre que conforma los acuerdos sociales, pero, por eso mismo, no sirve para promover una sociedad democrática puesto que su función es crítica y no construciva. Por ello, Rorty propone que se sea «ironistam o filósofo en privado y en la vida pública intentemos ser buenos ciudadanos sostenedores de nuestras democracias: "como ciudadanos y como teóricos sociales podemos ser tan indiferen- tes a los desacuerdos filosóficos sobre la naturaleza del individuo como Jefferson lo era sobre las diferencias teológicas acerca de la naturaleza de Diosw; 38 de hecho no se necesita una filosofía especial, ni siquiera una filosofía para dar con una buena política. Se puede ser buen ciudadano sin ser un conocedor de la filosofía. Aun con todo, queda por saber entonces si la ironía es un ejercicio connatural aunque innecesario a los hombres o si en próximas obras Rorty le reserva algo de más fuste y talante.

\section{La tradicion recuperada}

¿Cómo queda la filosofía analítica? Desde La filosofía y el espejo de la naturaleza, Rorty ha mostrado que la imagen que profesa el análisis es un autoengaño enganchado en metáforas propias de nuestra tradición de pensamiento, sus problemas son creados y pueden ser disueltos (al menos eso cree Rorty que hace); pero ¿después qué? Ahí es donde comienza el problema tal y como Bernstein ba intuido. ${ }^{39}$ Rorty podria haber optado por una solución a lo Dewey y decit qué es lo mejor y lo peor de una sociedad moderna, qué es bueno o malo; pero, aunque sugiere que la sociedad ha de ser conversación y no consenso, no da el establecimiento liberal deseable. El haber elegido este camino es lo que le lleva a la figura del «ironista» y a no saber cómo se puede relacionar la filosofía con la política - su filosofía con la política que él desea- ¿No es Rorty el más analítico por confiar tanto en la ciencia y sus tecnologías, sobre todo sociales, que no cree que la filosofia deba decir nada y así dejar a la sociedad moderna y científica a su libre avance? El mismo nos comenta que la filosofía analítica ha quedado hoy en un sestilo" por el que se reconocen los autores que proceden 
de esa comiente, en una unidad sociológica: el modo de escribir y de "señalizar" problemas de la generación que se ha educado dentro del análisis. Y como continúa diciendo, wel estilo analítico es, creo, un buen estilo. El ésprit de corps entre los filósofos analíticos es saludable y útil\%. ${ }^{40}$ Este estilo es el poder analizar problemas, el poder construir argumentos a favor o en contra de algo sin significar una realidad anterior a ese algo ni tampoco, como nos muestra el «ironista", posterior.

Creo que Rorty es un buen crítico de la tradición en la que se ha educado, mas sigue preso en ella, en ese miedo a dar el salto al vacío que puede ser la creencia - y profesión de fe- en las metáforas que el lenguaje crea. Bien es cierto que en la vida cotidiana el ciudadano pragmático no pone reparos a comulgar con ideas contingentes que funcionan como verdades tradicionales, pero el filósofo, en la imagen que el positivismo creó de él, no puede darse a tales alegrías si no es, claro está, en su privacidad. El esprit de corps analítico, hoy, según Rorty, es la posibilidad de la reflexión con rigor aun sabiendo que los filósofos uinventan problemas y programas de nowo" y que se caracterizan por no necesitar usaber de antemano cuáles son nuestros problemas y no necesitar proveer criterios de identidad que nos digan si nuestros problemas son los mismos que sus predecesoresw; 41 es cierto que esto parece innegable, como también ofrece pocas dudas el paralelo entre este modo de plantear la filosofía y el del filósofo todo rigor y no injerencia en lo social dentro de su laboratorio de análisis del lenguaje.

Al final, el pragamatismo rortyano pone nuevos modos de actuación a una tradicional postura ante la filosofía. La idea de Rorty es que el filosofo hoy no es sino la preocupación por poner la guinda en el pastel que han elaborado los sociólogos, los historiadores, los antropólogos, etc. No necesitamos más teoria porque los problemas que tenemos ahora precisan de soluciones concretas y experimentales", que se dan mejor usando un poco más de reportaje periodístico: "Nociones como "derechos del hombre", "plusvalia", "nuevas clases sociales" y otras han sido indispensables para el progreso moral y político. Pero no estoy convencido de que actualmente necesitemos de semejantes nociones" ${ }^{42}$ Si el «ironista” es un inútil social y es más fructífero atender a los periodistas, novelistas o antropólogos, no veo problema en arrinconarle y ponemos en manos de la literatura o la política a la hora de dar con nuevas redescripciones; pero, si la experimentación social ha de ser también enseñanza de nuevas generaciones y no mera propuesta de metáforas, entonces creo que no estaría de más que el rigor crítico del «ironista» - la tradicional función del filósofo- tuviera fuerza y espacio para presentar sus quejas. Aun cuando sólo fuera por no perder al viejo cascarrabias, vale la pena dejar abierta la puerta del laboratorio.
1. Consuzuences of Pragnatism, University of Minnesota Press, 1982, p. XVIII. Junto a este proceso está la importación de la filosofía continental y la aparición de nuevas preocupaciones como puede ser la feminista; pero, bien es cierto que la filosoffa analitica acostumbrada a bregar en aguas no siempre tranquilas es capaz de ignorar y no responder a estos nuevos planteamientos que aún considera en la perileria de la ocupación filosófica.

2. Quien desee un excelente esquema de como se desarrolla esta crítica en el libro citado, puede 
consultar el capitulo titulado "Philosophy in the Conversation of Mankind incluido en R.J. Bernstein, Philosophical Profiles, Oxford, Polity Press, 1986, cap. I.

3. Cuando el positivismo se planteo su acercamiento a la realidad lo hizo a traves del analisis del lenguaje que es donde se suponia que ésta se presentaba al mundo de los hombres fen claro enfrentamiento al analisis de las cosas mismas o de las cosas historiadas que eran las otras dos grandes comientes filosóficas de la epoca). Esta es la línea de Rorty que, con la filosofía hermenéutica, también critica el lenguaje positivista y deja paso a un pragmatismo que hace suyo el ya irrenunciable "giro linguístico", si bien comprendido de diferente manera.

4. Ver su The Linguistic Tum, University of Chicago Press, 1967.

5. Cr. aTranscendental Arguments, Self-Refe. rence, and Pragmatisms en P. Bieri, R.P. Horstmann and L. Krüger (eds.) Trascendental Arguments and Science, Dordrecht, D. Reidel Publishing Co., 1979, 77-103, p. 87.

6. "Representation, Social Practise, and Truth", Philosophical Studies, 54 (1988), 215-228, p. 223. ¿Por qué el filosofo analítico se pone nervioso ante esto? Porque es la fragmentación de los lenguajes y de las verdades sin que quede lugar a una unidad de investigación científica y además biede a metafisica.

7. La filosofía y el espeto de la naturaleza, $\mathrm{Ma}$ did, Cátedra, 1983.

8. "Trascendental. Arguments, Self-Reference, and Pragmatism*, p. 81 .

9. Para esto ver el articulo títulado *Method, Social Science and Social Hoper en Consegucnces of Praghratism. En último tếmnino los tipos de verdades se determinan por las exigencias del método - de conocer- que sea usado; como es obvio no hay método inocente que nos presente un juego de verdades indubitables. La verdad es cuestión de metáforas, de imágenes que nos presentan la realidad para nuestro mejor manejo de ella: "no hay nada profundo bajo nosotros excepto lo que hemos puesto nosotros mismns, ni criterio que no hayamos creado en el curso de creación de una práctica, ni estandar de racionalidad que no sea una llamada a semejante criterio, ni argumentación rigurosa que no sea obediencia a nuestras propias comvenciones,. Consequences of Pragmatism, p. XLII.

10. La filosofia y el espeto de la naturateza, p. 322 .

11. Cr. La flosofía y el espejo de ta naturaleza, p. $327 \mathrm{ss}$.

12. Cfr, «Representation, Social Practise, and Truth*, p. 220. Se puede uno imaginat la desesperación y estiramiento de cabellos analíticos ante alguien que niega esto. Precisamente uno de los origenes del análisis se sitúa en el deseo de Moore de establecer un sano sentido común ante las parece que comunes excentricidades de los metafísicos de su tiempo que dudaban de las sillas donde se apoyaban o del suelo que curiosamente no les llegaba a recoger.

13. Para esto es inevitable la referencia a "The World Well Losts en Consequences of Pragmatism. Es muy revelador, asimismo, el artículo titulado "Is There a Problem about Fictional Discourse* incluido en el mismo libro.

14. Dewey creía que el lin del conocimiento no era la búsqueda de una certidumbre intelectual, sino más bien un establecimiento que se hace verdad en el rendimiento que dé; James consideraba que la verdad era lo que podía producir y sustentar de forma exitosa una creencia. La idea según la cual verdad es lo que funciona, como se puede observar, está en los origenes del pragmatismo que Rorty abraza. Este trata de tener un claro objetivo: la máxima predicción, simplảcidad [...] de las teorias, pero no inmiscuüse en el motivo que nos induce a creer en ellas buscando una wcorrespondencia* que diga el porqué del éxito -a lo Putnam-... Tan sólo mostrar como funcionan.

15. Consequences of Pragmatism, p. 110.

16. w[El pragmatismo] dice que la verdad no es la suerte de cosa acerca de la cual se esperaría tener una teoría filosóficamente inferesante. Para los pragmatistas "verdad" es el nombre de una propiedad que toda aserción verdadera comparte [...] Los pragmatistas dudan que haya más que decir acerca de este común distintivo.s lbtiem. p. XIII.

17. Contingency, Iromy and Solidarity, Cambridge University Press, 1989, p. 8.

18. Rorty en este lugar gusta de parafrasear la diferencia entre ciencia normal y revolucionaria de Khun y los periodos de crisis $y$ de establecimiento de un nuevo paradigma. En electo, el distinto acercamiento al mundo establece novedosas imágenes y metáforas (dice de distinta forma la verdad) que han de inaugurar un periodo de in. vestigación «nomnal en el que tales imágenes pueden cobrar los atributos de una verdad absoluta y cstable. Considera Rorty que se traslada la noción de adescripción del mundox desde el nivel de criterio de las sentencias de un juego de lenguaje hasta el de los juegos de lenguajes como to. dos perdiendo, de este modo, el hábito de usar unas palabras y comenzando a usar otras que también describen el mundo.

19. Consequences of Pragmatism, p. XVIII. Más adelante repite: tel intento de decir "cómo el lenguaje relata el mundo diciendo qué hace a ciertas sentencias verdad, o a ciertas acciones o actitudes buenas o racionales, es, desde esta perspectiva, imposiblen, Bridem, p. XIX.

20. Confingence, Iromy, and Solidarity, p. 7. 
21. De hecho el lenguaje conecta de forma más fórrea quc las estructuras de nuestro conocer, el mundo con nuestro wonocimiento de al. Las estructuras del conocer imponian, al menos, que el espejo por mostrarse de frente estableciera un cruce de referencias (la izquiera resultaba a la derecha y vicecersa); esto es imposible cuando el espejo y su reflejo se sustituyen por la isomorfía y su identidad. Como se ve, el mismo paradigma cartesiano se perfecciona; las criticas elaboradas por Rorty en La filosofia y el espejo de la naturaleza quedan intactas y han de volver a ser aplicadas (como asi hace en el capítulo de su ultimo libro "The Contingency of Languagew) en este caso de depuración de *una imagen gastada".

22. Véase RI. Bernstein, op. cit., pp. 39-43.

23. Aun cuando es cierto que Ronty defiende una concepción de la filosofia destinada a analizar tradiciones $y$, en ellas, dar cuenta de la diversidad de valores, nunca hace de la historia algo que anule la contingencia del presente y la necesidad de dar soluciones desde cada momento determinado (soluciones que, si bien no son absolutas, se postulan para ejercer una coordinación social, y, de aquí, que no sean totalmente relativistas) por lo que considero que se puede acordar en general con la salvación de culpas que Bernstein le dedica.

24. "Trascendental Arguments, Self-reference, and Pragmatism", p. 91 .

25. La filosofia y el espejo de la naturaleza, p. 304. Para todo esto cfir. las pp. 301-311.

26. Ver aqui eThugs and Theorists\%, political Theon, 15, 4, noviembre (1987), pp. 564-580.

27. Para esto ver "Science as Solidarity" incluido en J.S. Nelson, A. Megill y D.N. McCliskey (eds.), The Retonit of Htkman Sciences, Madison, The University of Wisconsin Press, 1987, pp. 38-52.

28. Esto lo tomo de su Moral Identity and Private Autonomy, aún no publicado, p. 7 del manuscrito.

29. Cfr. aqui La filosoffa y el espejo de la naturaleza, p. 155 . Un poco más adelante en la p. 243 dice Rorty: "La idea de Dummet de la filosofía del lenguaje como "filosofia primera" nos parecerá equivocada no porque haya alguna otra árca "prmera" sino porque la idea de la filosofia en cuanto dotada de fundamentos es tan errónea como la de que el conocimiento tenga fundamento. Segín esta concepción, "filosofia" no es el nombre para una disciplina que aborda cuestiones permanentes [...] Es, más bien, un género cultural una "voz en la conversación de la humanidad" (en palabras de Michael Oakeshott), que se centra en un determinado tema y no en otro en un momento dados,

30. «Todas las crecncias que son centrales para la auto-imagen de una persona, lo son porque su presencia o ausencia sirve como criterio para divi- dir las buenas personas de las malas, la clase de persona que se quiere ser de la clase que no se desea ser. Una conviccion que puede ser justificada por cualquiera tiene poco interés. Contingente, Irony and Solidarity, p. 47 .

31. La fllosofia y el espejo de la naturaleza, p, 20.

32. Contingence, Irony and Solidarity, p. 48.

33. Esta cita se encuentra en "The Contingency of Community en The Londion Review of Books, 24 de julio (1986), y en su posterior reelaboración para Coningency, Iromy and Solidarity. Rorty la ha omitido.

34. The Priority of Democracy to Philosophy" incluido en Merrill D. Peterson y Robert C. Vaughan (eds.), The Virgin Statute for Religious Freedom, Cambridge University Press, 1988, 257-282, p. 274.

35. Analizadas y criticadas espléndidamente por Nancy Fraser en $x$ Solidarity or Singularity. Richard Rorty between Romanticism and Technocracy", Praxis Intemational, 8, octubre (1988), 257272.

36. Para esto que resulta paradojico cn quien se propuso dar cuenta, al modo pragmático, de cómo y qué podía el filósofo decir que fuera útil a su sociedad, debe verse el artículo de T. McCarthy "Ironia Privada y Decencia Pública: el nuevo Pragmatismo de R. Rorty., La Balsa de la Medusa, 9 (1988), 53-60. Remito a este articulo que da buena cuenta del motivo y el desarrollo de semejante contradicción.

37. Para todo esto cfr. La filosofia y el espejo de La naturaleza, pp. $289-290$ y Contingency, Irony and Solidarity, cap. 3. Se podría decir que los dos tipos de consideración del discurso - y de la sociedadconfiguran a su vez dos formas de concebir los comportamientos legitimados dentro de una comunidad política: así en tanto comunidad contendría dentro de si todas las actuaciones posibles (al igual que la ley cientifica puede reconstruir pasado y futuro porque todo tiempo es igual) con lo que sería lácil predecir el comportamiento de todos los individuos y las colisiones entre ellos se deberian a falla de conocimiento - siempre podrian ser arregladas (o condenadas para siempre), mientras que como sociedad no podria darse tantas alegrías y debería confiar en la aurbanidad* de sus niembros que, al tiempo, no serian capaces de conocer todo sobre sus semejantes. El imperio de la ley tiene sentido si no sólo sirve para protegerse, sino para conocer lo permitido y autorizado - lo posible-; el reproche continuo a Rorty es de qué modo en una sociedad contingente la ley puede cumplir tal función (la respuesta. asimismo, es invariable: debemos tomar la lay como si fuera ley inmutable hasta tanto no se ofrezca una altemativa).

38. "The Prionty of Democracy to Philosophy", p. 263. 
39. "Las cuestiones no pueden ser resueltas simplemente apelando a prácticas sociales existentes porque el corazón de la controversia es el serio y original conflicto de practicas sociales competentes, Op. cit, p. 51.
40. Consoquences of Progmatism, p. 217

41. Ibidem, p. 218.

42. Truth and Freedom: A Reply to $T$. McCarthy, aun no publicado, p. 17 del manuscrito.

\section{Ética y diferencia}

\section{AUGUSTO KLAPPENBACH}

No es la primera vez en la historia que al declive de la metafísica sucede un repentino interés por la ética. Cuando al fin de la época clásica los griegos vieron tambalearse los fundamentos de su visión del mundo, la filosofía no tardó en orientarse hacia la búsqueda de una respuesta a la única pregunta que no es posible evitar: ¿qué debo hacer? La acción es ineludible, y aunque puedan soslayarse algunas de las cuestiones teóricas propias de las épocas que Comte llamaría «orgánicas", parece difícil evitar una reflexión explícita acerca de la práctica, que se hace tanto más urgente cuanto menos puede fundarse en metarrelatos universalmente aceptados.

Quizá algo de esto sea lo que esté pasando en las sociedades postindustriales. Después de un merecido descanso, los temas éticos se han puesto de moda; proliferan los congresos, seminarios y publicaciones sobre filosofia moral, aun cuando no resulte fácil encontrar algún hilo conductor entre los diversos enfoques del problema. Las éticas comunicativas se reparten el espacio con neocontractualistas, nietzscheanos y posmodernos en general, lejos de toda posibilidad de encontrar una respuesta común en una época cuya cultura ha estallado en fragmentos en ocasiones incompatibles entre sí.
Esta misma dispersión puede constituir un tema digno de ser tenido en cuenta a la hora de pensar sobre este viejo problema. Tal vez hay que renunciar de una vez a la búsqueda de respuestas totalizantes y saludar la presente crisis de la metafísica como una oportunidad para que la ética encuentre su verdadero lugar en el conjunto de la cultura, emancipándose de la servidumbre a la que fue sometida durante muchos siglos por el pensamiento abstracto. Evidentemente - afortunadamente- el destino de la moral no depende de las elucubraciones de la ética; la filosofía moral sólo puede aspirar a una modesta reflexión acerca de una experiencia constitutiva de la condición humana que resulta slempre más rica que cualquier teoria que trate de dar cuenta de ella.

Pero no por ello resulta ocioso detenerse a examinar algunos signos de la cultura actual que puedan abrir nuevos caminos para este viejo tema. No se trata, por lo tanto, de inventar una ética de acuerdo con nuestros gustos sino de preguntarse si no existen razones para pensar que en nuestra "forma de vidas pueden encontrarse algunos gérmenes de una nueva manera de entender las relaciones humanas que contribuyan a liberar a la moral de algunas tiranías metafísicas, aun cuando estén 